\title{
Mesh-Related SIN Syndrome. A Surreptitious Irreversible Neuralgia and Its Morphologic Background in the Etiology of Post-Herniorrhaphy Pain
}

\author{
Robert Bendavid ${ }^{1 * \#, ~ W e n d y ~ L o u ~}{ }^{2}$, Andreas Koch ${ }^{3}$, Vladimir Iakovlev ${ }^{4 * \#}$ \\ ${ }^{1}$ Shouldice Hospital, Thornhill, Canada \\ ${ }^{2}$ Department of Biostatistics, Dalla Lan School of Public Health, University of Toronto, Toronto, Canada \\ ${ }^{3}$ Day Surgery and Hernia Center, Cottbus, Germany \\ ${ }^{4}$ Department of Laboratory Medicine and Pathobiology, Keenan Research Centre of the Li Ka Shing Knowledge \\ Institute; Division of Pathology, St. Michael's Hospital, University of Toronto, Toronto, Canada \\ Email: ${ }^{\text {rbendavid@sympatico.ca, }}$ iakovlev.v@gmail.co
}

Received 17 May 2014; revised 16 June 2014; accepted 15 July 2014

Copyright (C) 2014 by authors and Scientific Research Publishing Inc.

This work is licensed under the Creative Commons Attribution International License (CC BY). http://creativecommons.org/licenses/by/4.0/

(c) (i) Open Access

\begin{abstract}
Purpose: The ubiquitous use of synthetic materials in hernia surgery has brought about a new clinical syndrome: Surreptitious Irreversible Neuralgia (SIN). It is surreptitious because it is of slow onset, unsuspected and enigmatic to clinicians; irreversible because the pain is progressive, unrelenting and unresponsive to treatment. Removal of the mesh does not guarantee pain relief. Neuralgia following mesh insertion, when it occurs, remains a poorly understood phenomenon. Methods: Ten specimens in each group: virgin tissue, scar tissue and explanted mesh from the posterior inguinal wall were examined histologically to assess nerve density, nerve size and nerve and vessel ingrowth into the deformed mesh and within its pores. Results: There was no significant difference in nerve density between virgin, scar and mesh samples. All of the explanted meshes had nerves within the scar tissue encasing the mesh (interstitial infiltration). Nerve ingrowth through the pores of the mesh (micro-entrapment) was detected in $90 \%$ of the explanted mesh specimens. Additionally, nerves were detected entrapped within the folds and deformations of mesh explants. Ingrown vessels showed congestion and focal fibrin thrombi. Conclusion: The presence of mesh does not significantly affect nerve density, while the nerves and their terminal ends are in a vulnerable position about the mesh and within its pores. These pores need to be viewed as "mini-compartments" of biological tissue where the vasculature, nerves and their receptors are exposed to potential mechanical and chemical factors: scarring, entrapment, compression, tugging, deformation, contraction, hypoxia/acidosis, inflammation and edema.
\end{abstract}

\footnotetext{
*Corresponding authors.

${ }^{\#} \mathrm{RB}$ and VI have acted as consultants on medico-legal issues covering polypropylene meshes. No grant nor funding supported this research work.

How to cite this paper: Bendavid, R., Lou, W., Koch, A. and lakovlev, V. (2014) Mesh-Related SIN Syndrome. A Surreptitious Irreversible Neuralgia and Its Morphologic Background in the Etiology of Post-Herniorrhaphy Pain. International Journal of Clinical Medicine, 5, 799-810. http://dx.doi.org/10.4236/ijcm.2014.513107
} 


\section{Keywords}

\section{Polypropylene, Mesh, Mesh Pores, Hernia, Pain, Nerves, SIN Syndrome}

\section{Introduction}

There has been, in the sphere of abdominal wall reconstruction, what can only be described as a tidal wave of olefins submerging the operating rooms of the world. Polypropylene, the most extensively used olefin [1] [2] has helped displace Pure Tissue Repairs of inguinal hernias to contribute to the "new gold standard" in hernia repairs - the Tension Free Repair [3]-[8]. It would seem that recurrences are now under check. But are they? Professor V. Schumpelick, Editor-in-Chief of the Journal HERNIA, addressed the American Hernia Society in February 2005 at San Diego (CA) and stated and repeated since that "In the last 30 years, despite the introduction of meshes and laparoscopic surgery, there has been no improvement in the incidence of recurrences" [9].

While the best results with mesh repairs have not outperformed the best Pure Tissue Repairs [10] in the hands of experts, the new emerging problem is that of pain, post-operative pain currently described as inguinodynia. Its high-incidence following anterior repair (28.7\% - 75.5\%) [11]-[13], open and laparoscopic repairs (12\% - 30\%) [14]-[18] are a concern, which is leading to troublesome litigation [19]. Though thousands of patients appear to be affected, according to the non-profit National Meshoma Foundation [20], the magnitude of the problem has not been acknowledged by the industry or the profession at large. To investigate potential causes of pain we assessed the histological appearance and organization of explanted mesh specimens. To test whether the presence of mesh has an effect on innervation of scar tissue, we investigated nerve density and distribution in virgin tissue sampled at operative sites during primary hernia repairs as well as in tissues sampled during non-mesh recurrent hernia repairs and mesh explants. The mesh in question is polypropylene, the most widely used polymer in hernia repair [1] [2].

\section{Methods}

After approval by the Shouldice Hospital administration for ethical considerations, the following 30 samples were collected starting January 2013: virgin tissue from the posterior wall of the inguinal canal of 10 primary inguinal hernia repairs, scar tissue from the posterior inguinal wall of 10 hernias which had previously been repaired by pure tissue repair, and 10 mesh explants of hernias which had previously been repaired with monofilament polypropylene mesh as an onlay (Lichtenstein). Reasons for the surgical intervention were the presence of a hernia or a recurrence with pain/discomfort. The tissue has been fixed in $10 \%$ neutral buffered formalin for at least 48 hours before processing. The virgin tissue and scar samples were submitted entirely into paraffin blocks. The mesh specimens were sampled initially by two blocks, then, if nerve ingrowth was not detected within the initial two blocks, additional blocks were taken until penetration was detected. The tissue was handled according to the routine laboratory standard operating procedures. The tissue was sectioned at $4 \mu \mathrm{m}$ and stained with hematoxylin and eosin (H \& E) and immunoperoxidase for S100 protein to highlight peripheral nerves (DAKO rabbit polyclonal Z0311, enzyme digestion for 4 minutes followed by incubation for 16 minutes, 1:1000 dilution; Ventana Benchmark XT).

If a peripheral nerve was seen inside an imaginary line connecting the outermost points of adjacent mesh filaments, it was recorded as nerve ingrowth into the mesh pore. If a nerve was seen directing itself towards a pore but skirting it, and then showing a general course parallel to the mesh, it was not considered as ingrowth into the pore. Density of peripheral nerves was assessed by scanning all tissue at $200 \times$ magnification (20× objective, $10 \times / 24$ eyepiece) and recording the number of nerves and the number of $200 \times$ microscopic fields. Then a ratio of nerves/200× fields was calculated per specimen. Since the mesh material occupies non-viable space within tissue, which could lead to underestimation of nerve density, we calculated an adjustment ratio. Ten images of random areas of the specimens were processed to generate two sets of binary (black \& white bitmap) images: a set of images of all tissue including mesh filaments and a set of images excluding the mesh filaments. Selection, thresholding and image conversion were done using Photoshop SC6 (http://www.adobe.com/) and area measurements using image analysis software HAPI [21]-[23]. Median percentage of area occupied by the mesh material within the sampled tissue was $7.3 \%$ and an adjusted nerve density was corrected accordingly. 


\section{Results}

Routine H \& E examination showed that virgin tissue samples represented unremarkable connective tissue; the scar samples-variably dense collagenous scar related to previous surgery; and the mesh samples included mesh structure, surrounded by connective tissue. At low magnification, the mesh showed flat segments as well as parts with variable deformations: edge curling, folds, tight multilayered rolls and more complex deformations (Figure 1). All mesh specimens showed the same microscopic architectural organization formed by monofilaments in groups ("knots"), variably spaced in keeping with a knitted pattern. The spaces between filaments were filled with scar and, focally, adipose tissue. The scar tissue was mature and collagenized, with good vascularization
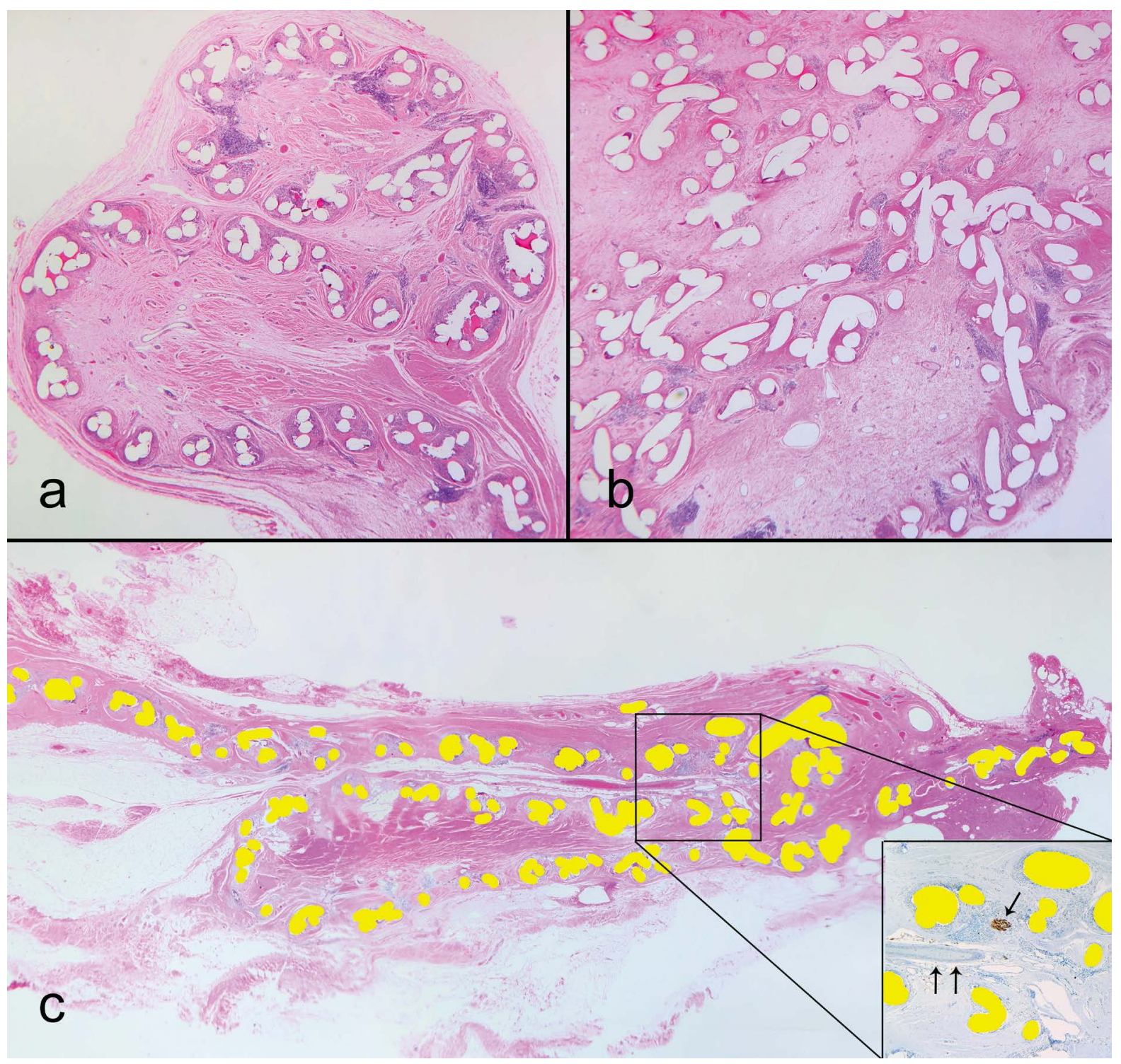

Figure 1. Mesh deformations; haematoxylin and eosin (H \& E); magnification (a) 25×, (b) 40×, (c) 10×. (a) Curling deformation. Cross-sectioned mesh filaments appear as white (transparent) holes. The mesh folded in an S-shape with a curled edge and is fused in this position by the surrounding scar; (b) A more complex deformation, likely intraoperative and intentional. Note that the density of connective tissue is changing: scar surrounding filaments and edematous tissue in the middle of the compartments; (c) A sliding Z-shaped fold. Mesh filaments are filled yellow (bright white for greyscale printing). In the insert: S100 stain, single arrow points to a nerve, double arrows to an artery. Note the neurovascular bundle inside the top folding point. The bundle has a layer of loose connective tissue around it, which indicates the mesh likely slid under it postoperatively, rather than the bundle grew into the fold. 
with vessels, some of which ran through the mesh pores. Overall, the appearance was of ingrown tissue compartmentalized by the mesh structure. There was congestion of the vessels within the pores which was more pronounced, within the mesh deformations (Figure 2(a)). In four cases we observed areas of fat necrosis (Fig ure 2(b)) and in two cases fibrin thrombi within capillaries (Figure 2(c)). Tissue within more complex deformations showed edema (Figure 2(d)). Most monofilaments were surrounded by a variable degree of foreign body type giant cell inflammatory reaction while none of the samples had acute inflammation.

Immunohistochemical staining for S100 protein highlighted peripheral nerve branches, which were present singly as well as within small neurovascular bundles. The branches located at the mesh interface tended to have an orientation parallel to the mesh plane. Some branches showed a course angled to the mesh plane and 9 out of the 10 mesh specimens (90\%) showed penetration of nerves into the mesh structure (Table 1). As described if a

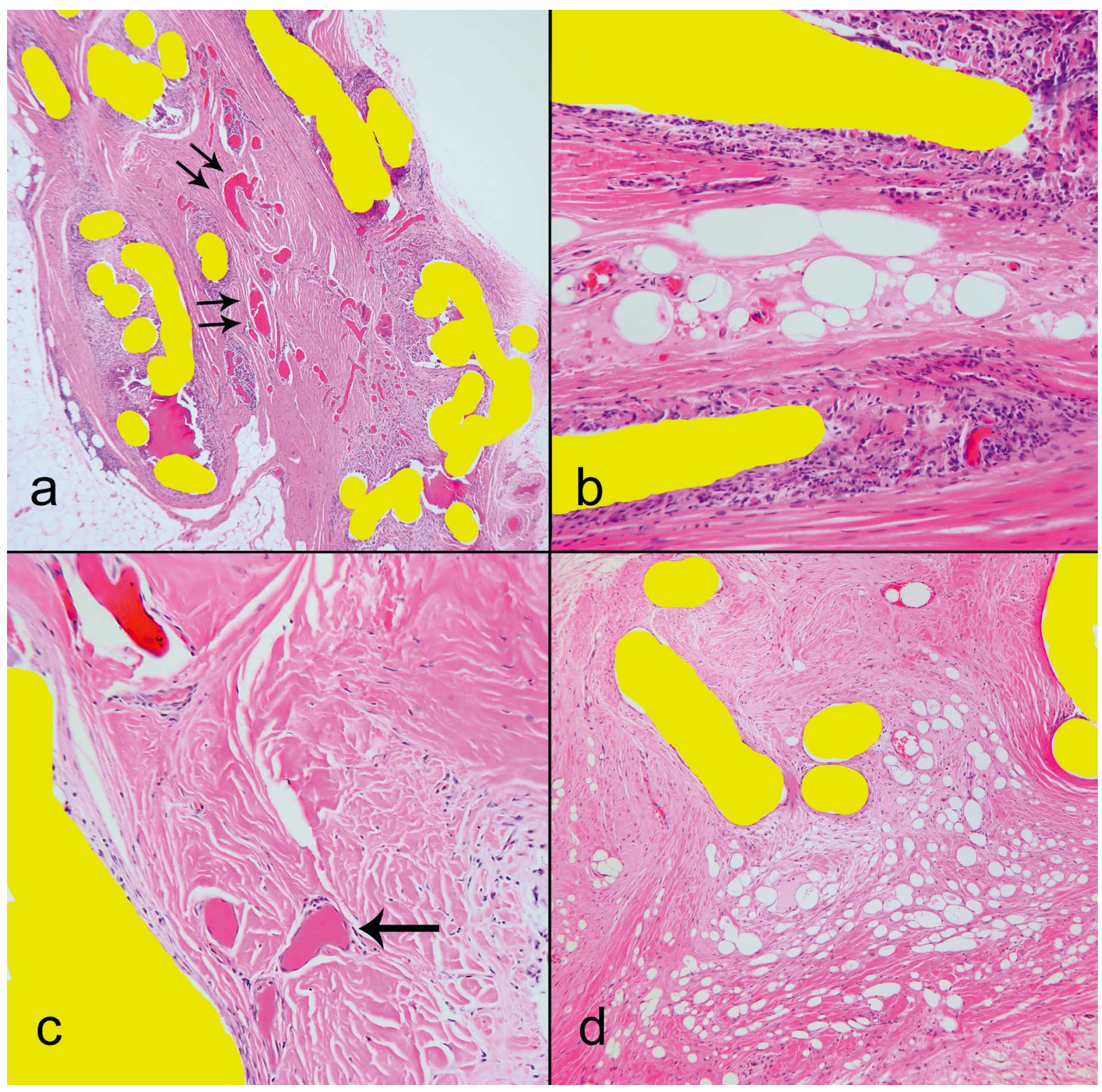

Figure 2. Microscopic H \& E findings, magnification (a) 40×, (b) \& (c) 400×, (d) 200×. Mesh filaments filled yellow for publication. (a) Congested capillaries within a deformation compartment (double arrows point dilated congested capillaries); (b) Fat necrosis between mesh filaments; (c) Thrombosed capillaries (arrow). Compare the color of fibrin thrombi in the lower part of the image and a congested capillary in the upper left corner; (d) Extreme degree of edema of tissue within mesh compartments where the fluid formed microcavities. 
nerve was present inside the mesh structure, it was considered as ingrowth (Figure 3). The number of nerves ingrown into the mesh structure ranged from 1 to 3 per examined portion of a specimen. While 1 - 3 nerves seem like a small number, one must remember the overall small mesh area sampled in the histology sections. Table 1 provides examined tissue area. For example 50 microscopic fields at 200× magnification represents 3 linear $\mathrm{cm}$ by 4 microns (section thickness) wide or $3 \mathrm{~cm} \times 0.0004 \mathrm{~cm}$ i.e.: 0.0012 square $\mathrm{cm}$ of mesh area. These calculations translate into several thousand ingrown nerves if one considers the surface area of an entire mesh! We did not detect a correlation of the number of ingrown nerves with the total number of nerves within the specimens (Spearman $=0.07, \mathrm{p}=0.85$ ). These $1-3$ ingrown nerves into the pores constituted a median of $6.3 \%$ (range $2.17 \%$ $-15.8 \%$ ) of all nerves seen within the examined tissue (Table 1). We detected no indication that the scar around

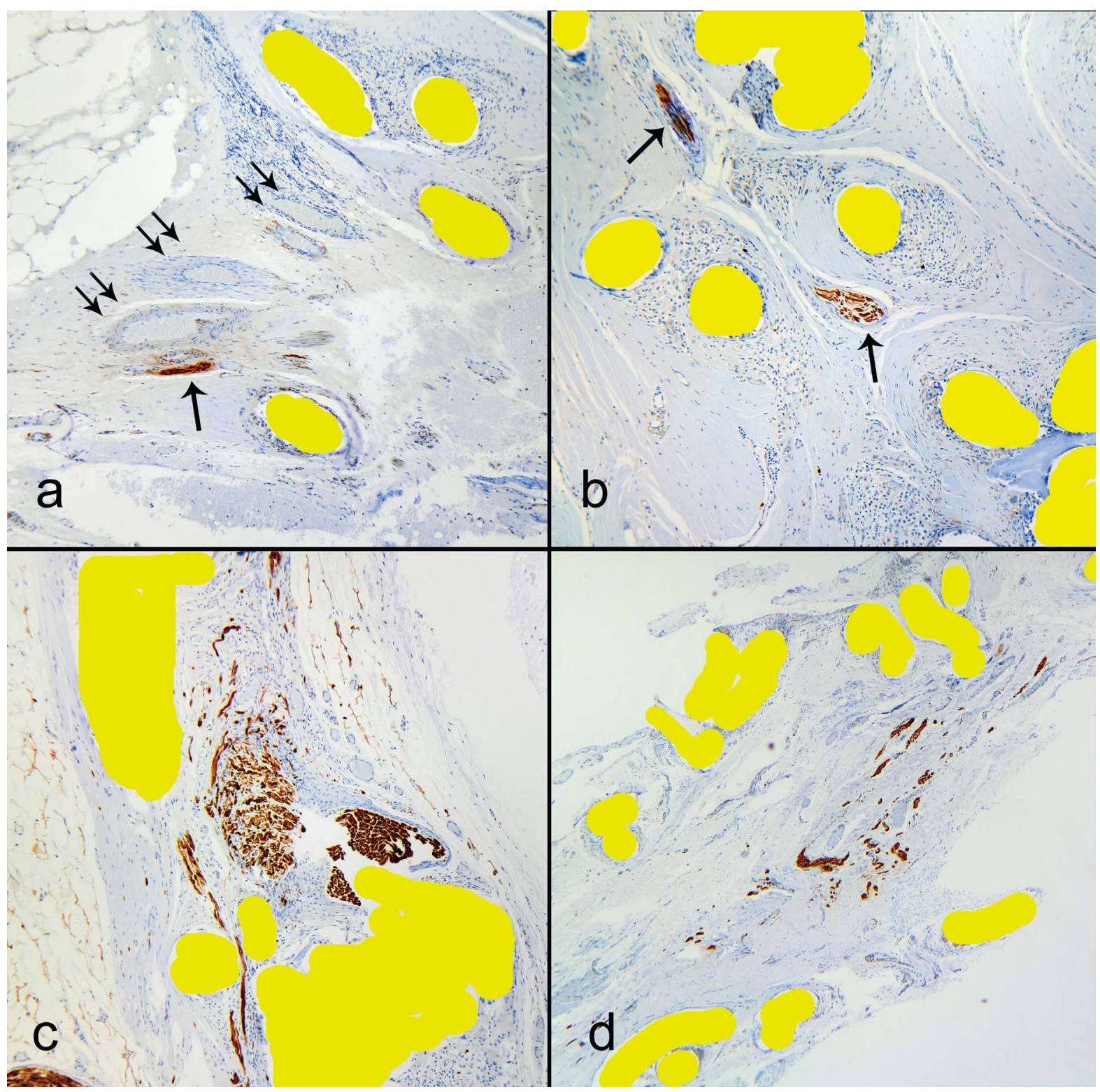

Figure 3. Nerve ingrowth into the mesh structure. S100 immunostain, nerves are labeled by brown color. Magnification: (a) $200 \times$, (b) $400 \times$, (c) $400 \times$, (d) $100 \times$. (a) Several vessels and a nerve grow in a bundle through a narrow space between mesh filaments. Nerve-single arrow, vessels-double arrows; (b) Two nerves within mesh structure, where the position is in the middle of mesh thickness, through the filament knots and parallel to the mesh plane; (c) A tight fit of a larger nerve ( 1.0 $\mathrm{mm}$ ) in a mesh pore. Note a smaller branch in the lower half makes its way through a slit-like space; (d) A bundle of peripheral nerve branches sandwiched between two layers of mesh. 
R. Bendavid et al.

Table 1. Nerve assessment data.

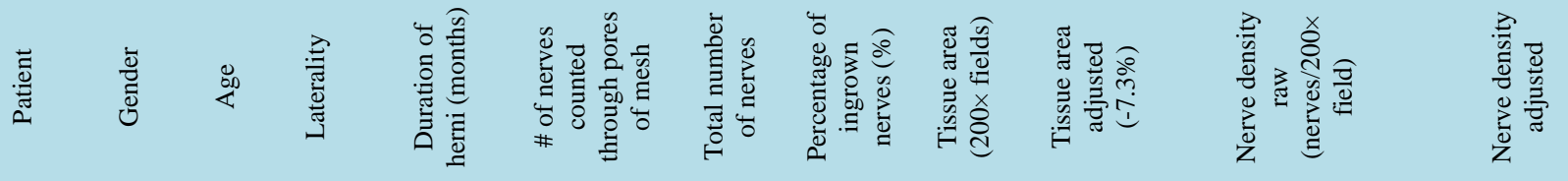

\section{Virgin tissue}

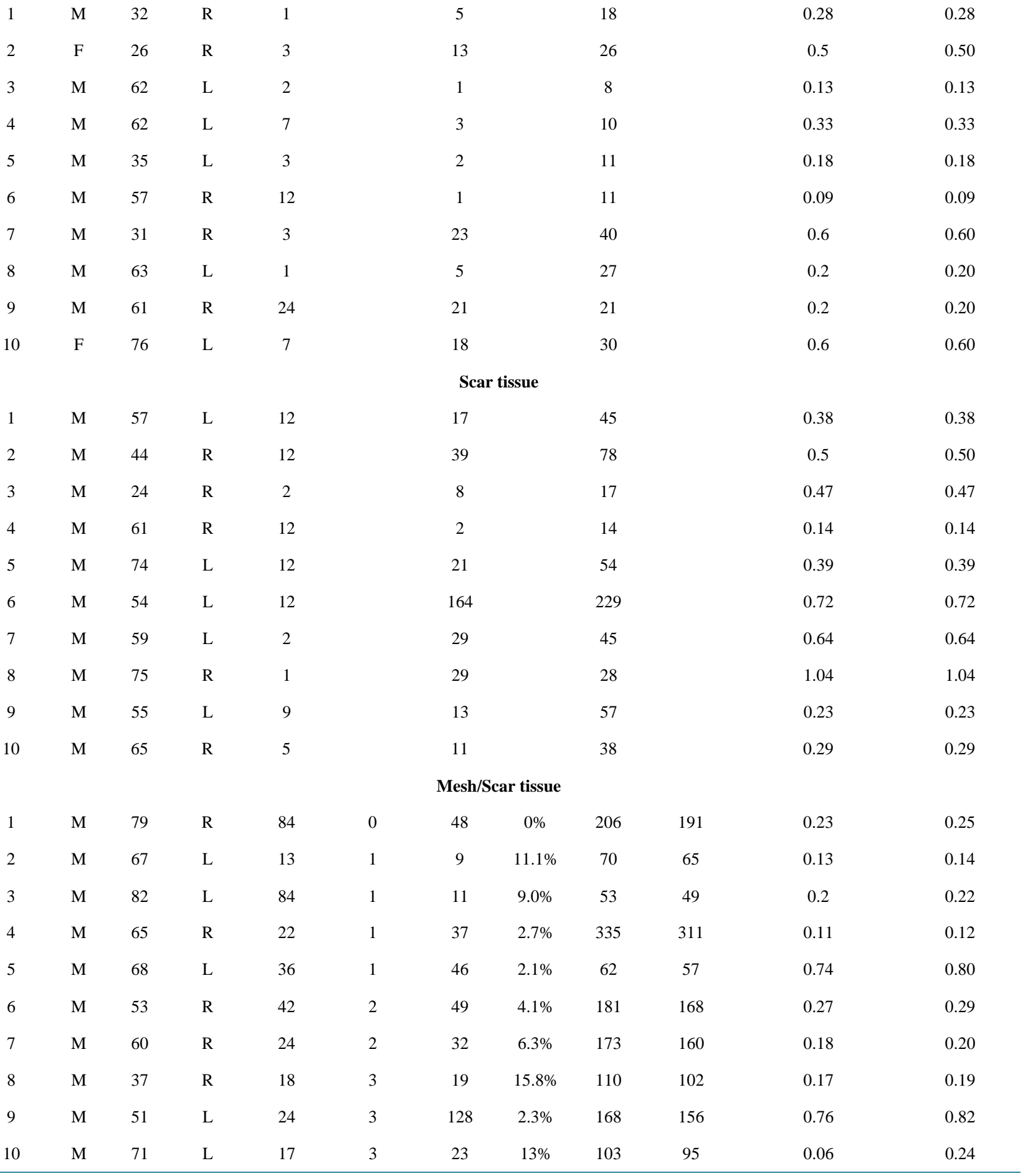


and within the mesh has significantly lower innervation than an ordinary scar. The latter has been shown, in other studies, to have a higher number of nerves than normal tissue [24] [25].

Nerve density was assessed within the three groups by counting the number of nerves within $200 \times$ microscopic fields. Since mesh material occupies non-viable space, we also calculated adjusted density values for mesh specimens. The median nerve density was $0.24,0.43,0.19,0.23$ nerves/200× field for virgin, scar, mesh unadjusted and mesh adjusted assessments respectively (range 0.09 - 0.6; 0.14 - 1.04; 0.06 - 0.76; 0.12 - 0.82) (Figure 4).

The scar samples showed a trend for higher nerve density, however the difference was not significant (KruskalWallis test, $\mathrm{p}=0.1$ using unadjusted mesh values, and $\mathrm{p}=0.16$ for adjusted values). Although median values for the mesh group were lower than that of the scar without mesh, the difference was not significant. The difference was smaller yet for adjusted values. This was in keeping with published innervations within scar tissue [21] [22] [26] [27].

There were several findings pointing to postoperative deformation and migration of the mesh. The finding of Z-shaped folds, where the folding point was around a neurovascular bundle suggested sliding of the mesh postoperatively (Figure 1(c)). Another finding indicating mesh migration was integration of striated muscle into the mesh structure (Figure 5(a)). The most dramatic evidence of postoperative migration was the finding of a larger nerve deformed and stretched by the mesh (Figure 5(b)). The shape of the nerve indicates an active mesh migration into the nerve, rather than passive nerve growth around the mesh edge.

The last set of measurement concerned the thickness of nerves ingrown into the pores of the polypropylene mesh. They ranged from $0.02 \mathrm{~mm}$ to $0.9 \mathrm{~mm}(20$ to $900 \mu \mathrm{m})$; the average was $0.08 \mathrm{~mm}(80 \mu \mathrm{m})$; the median was $0.03 \mathrm{~mm}(30 \mu \mathrm{m})$. At $0.9 \mathrm{~mm}$, the size is not too dissimilar from that of the ilioinguinal or iliohypogastric nerves.

\section{Discussion}

The sphere of hernia surgery has evolved at galactic speeds in the last thirty years, coaxed by a plastics industry which was only too happy to supply the demands for olefin derivatives. The indolent years of the barber surgeons and anatomists terminated with Edoardo Bassini who single handedly marked the beginning of a surgical Renaissance [28]. A mini-revival took place with the re-discovery of Bogros [29] and Fruchaud [30] for a better understanding and application of anatomy which easily transferred to Tension Free and Laparoscopic Repairs. Today's leitmotif in hernia surgery, to accompany the newer techniques, has been the extensive use of prosthetic materials.

The philosophy of Tension Free Repair, which was made possible by the advent of synthetic materials was born in Marseille, France, fathered by Don Aquaviva in 1944 [3] who used sagittate nylon sheets as an onlay

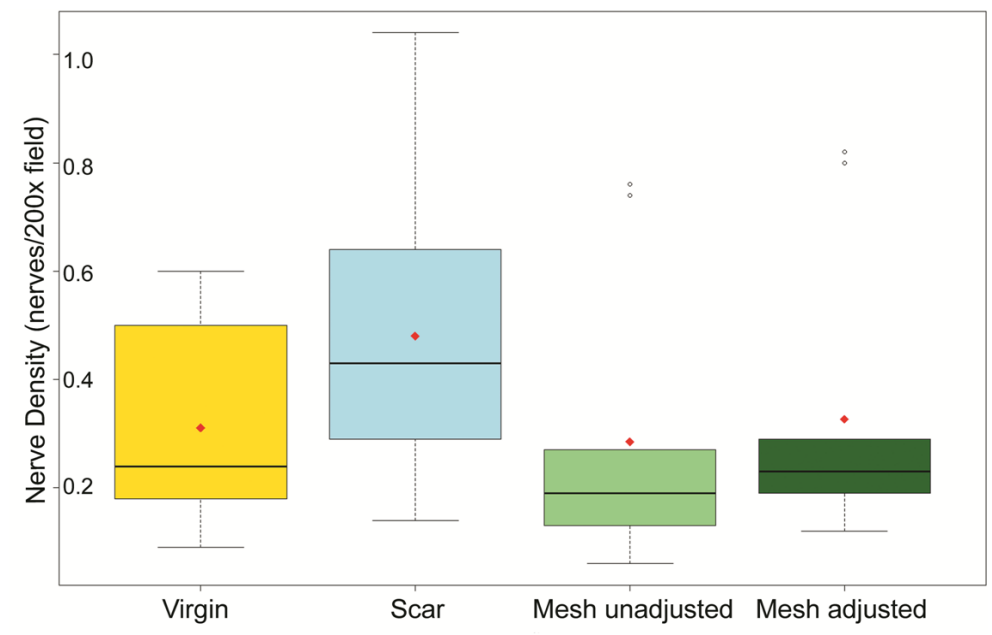

Figure 4. Nerve density within three groups of tissue samples: virgin, scar and mesh (unadjusted and adjusted for the "dead space" occupied by polypropylene). There was a trend for higher nerve density in scar, however the difference was not significant (Kruskal-Wallis test, $\mathrm{p}=0.1$ using unadjusted mesh values, and $\mathrm{p}=0.16$ for adjusted). Lower values for mesh specimens were not significant as well. 

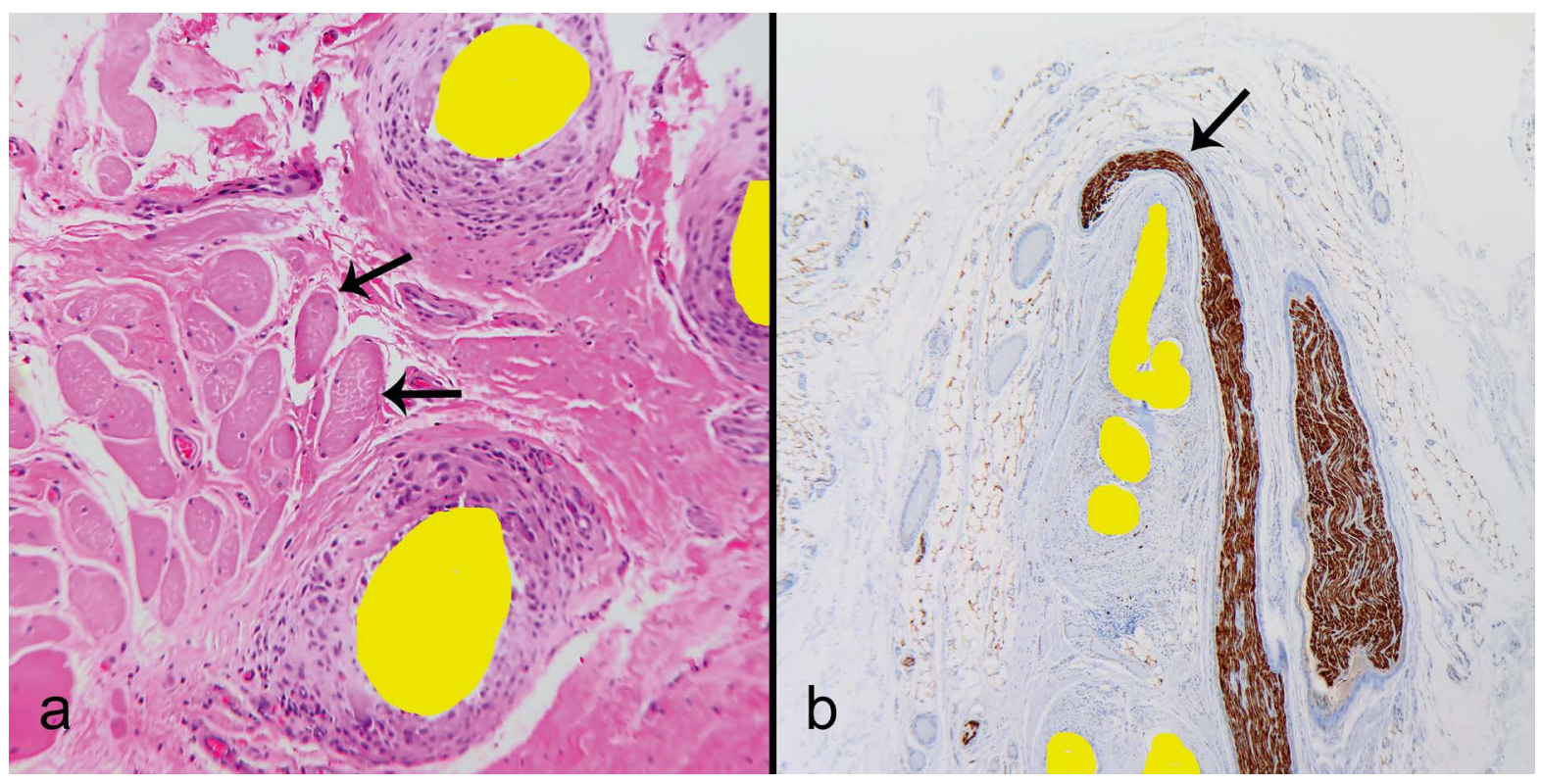

Figure 5. Findings indicating postoperative mesh migration and important mesh-tissue interactions. (a) Striated muscle anchored to the mesh. Note the muscle fibers (arrows) within scar tissue between the mesh filaments. The mesh likely migrated towards the muscle. In this position muscle contraction tugs the mesh with its compartmentalized tissue components; (b) A dramatic example of mesh migration into a peripheral nerve. The nerve is severely distorted and stretched by the edge of a mesh migrating towards the nerve.

over a defect which itself was left intact. The theme was re-visited by Henri Fruchaud in 1956 ([31] pp. 297, 299, 301) who designed an operation, also using nylon mesh, in a manner which antedated and precisely anticipated (Francis Usher [31], pp. 297, 299, 301). Usher provided the polyethylene then polypropylene while reproducing Fruchaud's technique [32]. Richard Newman of Rahway, New Jersey presented 350 cases of tension free repairs with polypropylene à la Aquaviva in 1956 and Irving Lichtenstein credited Newman for having "utilized a technique almost exactly as I had envisioned it" [33]. This generous, sincere and selfless declaration by Irving Lichtenstein appeared in the preface to his second edition of "Hernia Repair without Disability" (1986).

While several surgical techniques based on the principles of Tension Free Repairs have been introduced in the last 30 years, polypropylene has become the dominant olefin utilized to that end [1] [2]. The use of prosthetic materials has become an accepted and recommended standard in most surgical centers in the world and even recommended by the European Hernia Society [34]. Such enthusiasm has been dampened through an editorial by Josef Fischer of Harvard who underlined some of the shortcomings of indiscriminate use of plastic meshes [35]. The plastics industry wasted no time in producing Marlex [HDPE (High Density Polyethylene) and crystalline polypropylene], a synthetic polymer discovered by J. Paul Hogan and Robert Banks of the Phillips Petroleum Company.

This discovery was made possible thanks to the pioneering work in olefin chemistry by two Nobel Prize Laureates (1963): Giulio Natta and Karl Ziegler.

The interest in studying the behaviour of nerves in healing tissues of the groin was prompted by an unexpected and unpredicted prominence of pain as the commonest complication of mesh groin hernia repairs today [11]-[18]. This complication was never reported or published as a series by the Shouldice Hospital because it had never been deemed a common complication of Pure Tissue Repairs. Certainly no large series could be identified. This is not to say that it does not occur. Pain following inguinal hernia repair was first recognized, at least in modern times, by a Canadian, R.K. Magee in 1942 and referred to as "Inguinofemoral Causalgia" [36]. Three years later, in 1945, another Canadian, E.K. Lyon reported that the causalgia was surgically correctable [37]. A third clinical instance of inguinodynia, dysejaculation, was added by another Canadian, R. Bendavid of the Shouldice Hospital in 1992 [38].

The mechanisms of neuralgia are varied, complex and several explanations and classifications have been put forth. The simplest and all encompassing was provided by J.P. Chevrel [39] whose description may be summarized here. All presentations have an acute or chronic point tenderness felt along the nerve course and its 
cor-responding dermatome. The different types of pain are neuroma pain, deafferentation pain, projected pain and referred pain. With referred pain, dermatome and cutaneous viscerosomatic segments may be confused. The causes of pain are a partial or total division of a nerve, irritation, inflammation, section, compression, entrapment, burn, anoxia and neuroma formation.

The new ingrowth of nerves into the pores of a mesh, after scarring is set in place, can be compared to the entrapment of a nerve trunk (ilioinguinal, iliohypogastric or any offshoot) by a suture. Relief in the latter situation can be expected when the complication is recognized and the release of the said nerve is effected within a reasonable period of time. Ideally within a month and certainly no later than six months as the chronicity of the pain may become problematic due to psychological mechanisms which are poorly understood [40]. Even removal of the entire mesh may not resolve a pain problem and this is reminiscent of the "phantom pain" seen with amputations. A mesh, however, is rarely perceived as a living structure capable of nerve entrapment or one endowed with its own vasculature and innervation.

Having compared virgin tissue, scar tissue without mesh, and mesh specimens from a similar anatomical sitethe inguinal canal-we observed no indication that the mesh significantly inhibits or promotes nerve growth in the surrounding scar. The process of filling and organization of the spaces around and within the mesh during the course of tissue repair appears to be non-specific with reference to the growth of nerves and vessels. The direction of nerve growth is influenced by mechanisms of alignment which aim to restore neo-innervation along adjacent myoaponeurotic tissue planes. Ultimately, the nerves supply axons to receptors, including those of pain. We observed nerves growing into the mesh pores in almost all cases (90\%), where the ingrowth was focal and detection was dependent on sampling. Statistically, ingrowth appeared to be random (Table 1).

Although our main intention had been the detection of nerve ingrowth, we observed other mechanisms by which the nerves and their endings would become exposed to mechanical and chemical noxious stimuli. Gross mesh deformations seen with naked eyes, provide additional opportunities for nerve and vessel entrapment. A mesh folded or curled during or after surgery provides extra spaces for ingrowth, while later deformations and shrinkage [41] can warp the whole mesh-scar plate including the ingrown and adjacent nerves and vessels (Figure 1 and Figure 3). Pores, deformation, edema, scarring and warping provide a "micro-compartment" setting for the development of a neuralgia. Each pore becomes a potential pinch point.

In order to avoid or delay such pinch points, the industry has developed new, lighter meshes with larger pores. These newly designed meshes, while having larger pores, the latter necessitate peripheral support through a much smaller weave/knit pattern which recreate the smaller pores! Examining the new meshes under a microscope, we estimated that a $10 \times 7.5 \mathrm{~cm}$ rectangle of polypropylene has between 4000 pores (Prolite mesh) to 20,000 pores (Trelex and Marlex meshes). The pore openings measure $1.2 \times 1.5 \mathrm{~mm}$ (Prolite) and $\sim 0.65 \times 0.55$ $\mathrm{mm}$ (Marlex and Trelex). Micropores surrounding the macropores in both designs range from 0.6 to $0.1 \mathrm{~mm}$ and smaller. For comparison, the size of the ingrown nerves in our set ranged from several axons thick $(\sim 0.02 \mathrm{~mm})$ to sizable branches of $\sim 1.0 \mathrm{~mm}$ thickness. The thickest nerve had a "tight fit" between the mesh filaments (Figure 3(c)). Blood and lymphatic vessels ranged in size from capillaries (30 - $40 \mu \mathrm{m})$ to small veins and arteries $(0.2-0.3 \mathrm{~mm})$. Presence of vessels in the compartments (pores and deformed spaces) is a risk factor for disturbances of fluid and hemodynamics. We observed congestion, capillary dilatation, edema, focal fibrin thrombi and areas of fat necrosis (Figure 2). These findings point further that the nerves and receptors are not only vulnerable to external pressure and deformation, but also to edema, with raised micro-compartment and micro-entrapment pressures, but also to a hypoxic and acidic environment. Additionally, background chronic inflammation can provide vasoactive mediators and affect the sensitivity of pain receptors [24] [25]. To understand the complex interactions between the olefins and biological tissues, their site of contact needs to be studied as a compartmentalized, living tissue. Additionally, tissue forces and chemical environment affect the mesh, which in turn may have an effect on tissue components. For example, Figure 5(a) shows that the mesh, forced to migrate by the tissue, deforms and stretches a nerve. Figure 5(b) captures an anchoring point of striated muscle to the mesh. One of the tissue effects on polypropylene is degradation manifesting as cracking of the filamentous surface and indicating a change in mechanical mesh properties [41]. Expansion or shrinkage, where variatiation can range from $-40 \%$ to $+58.5 \%$ [41] affects all compartments within the mesh structure and their contents. The newer, lighter meshes with larger pores (macropores) but associated now with several smaller surrounding pores (micropores) are not likely to eliminate the potential for entrapment, compartment syndrome and the SIN syndrome.

The intra-operative and postoperative folding, slippage, displacement, edge curling, complex distortions, mi- 
gration (from the original site) and transmigration (through an adjacent structure) [41] [42] add another layer of complexity to interaction between the mesh and human tissues. The need to understand the behaviour of olefins in humans is becoming more important than ever. No longer is it necessary to work on mice, rabbits, dogs, pigs. The majority of hernia repairs today are done with some form of prosthesis and complications are seen often enough to study patients and their explants. Of these complications, pain has been the most prevalent and consistent symptom. As we acquire more expertise in the handling of this class of patients, we are observing that those patients who are likely to be abandoned, when pain is a major issue, are those patients whose surgery has been done laparoscopically. Perhaps because of the fear of re-operating in a field made technically more difficult due to adhesions of mesh to urinary bladder, iliac and femoral vessels, a denuded vas deferens, segments of the colon, Fallopian tubes and fimbriae. One observation, common to all reviews of operative notes in the attempt at removal of laparoscopically inserted mesh, is that the foreign body "has not been entirely excised". It is well to consider that if a hernia repair is done laparoscopically, it should be considered essentially irreversible. Often, when a hernia repair has been done laparoscopically, attempts at correction of pain and or recurrence, the chosen approach may be an open anterior access and such a choice may not address the problem of pain for which the patient sought relief.

A "Mesh Retrieval Registry" has been set up by the present surgeons and pathologist and several colleagues have volunteered to participate for an in-depth study of the "Mesh-Pain" problems. A protocol will be addressed to all who would be willing to participate and contribute. Reports of such a surveillance are sure to find their way, on time, in the surgical literature. For a certain, very small segment of the surgical population, prostheses may be here to stay and it then behooves all of us to understand their pathophysiology. The next step will be the correlation of histology/pathology to the clinical presentation and severity of pain. This is presently being done and will form the basis of a later publication. While knowledge comes, let us translate it into the wise application for which it was meant. This is the duty of our profession. It is an oath which we must honour proudly, disconnected from any notions of personal or commercial conflicts of interest.

\section{Conclusion}

Polypropylene has emerged as the principal olefin in the construction of surgical meshes. Its use has been associated with a high incidence of post-herniorrhaphy pain. An established cause of reversible post-operative pain in hernia repairs has been nerve entrapment; its treatment is simple-release of the entrapped nerve by removing the offending suture or by resecting the traumatized nerve. It is felt that the mechanism of pain associated with the use of mesh may similarly be due to "micro-entrapment" and "micro-compartment" types of syndromes through new nerve and vessel ingrowth within the mesh pores and other confining spaces with the concomitant edema, anoxia, thrombi, scarring, distortion, migration and traction. Because the onset of pain is slow and progressive (surreptitious), and because it may become irreversible if not treated early, the neuralgia has been labelled as the SIN syndrome. It is hoped that the proper understanding of the behaviour of polypropylene implantation in humans will contribute to a lessening in incidence of chronic post-herniorrhaphy pain and debilitation.

\section{Acknowledgements}

We would like to acknowledge the support and contributions of Dr. Shouldice, the surgeons of the Shouldice Hospital, Eric Frysberg, Karl Seebach of Information Technology and Catherine Hill and her staff in charge of archives.

\section{References}

[1] Lefranc, O., Bayon, Y., Montanari, S., et al. (2011) Reinforcement Materials in Soft Tissue Repair: Key Parameters Controlling Tolerance and Performance-Current and Future Trends in Mesh Development. In: Von Theobald, P., et al., Eds., New Techniques in Genital Prolapse Surgery, Springer Verlag London Ltd., London.

[2] Akolekar, D., Kumar, S., Khan, L., et al. (2008) Comparison of Recurrence with Lightweight Composite Polypropylene Mesh and Heavyweight in Laparoscopic Totally Extraperitoneal Inguinal Hernia Repair: An Audit of 1232 Repairs. Hernia, 12, 39-43. http://dx.doi.org/10.1007/s10029-007-0275-7

[3] Acquaviva, D.E. (1944) Societé de Chirurgie de Marseille. 
[4] Acquaviva, D.E. and Bourret, P. (1948) Notes de Techniques Chirurgicales. La Presse Médicale, 73, 18.

[5] Acquaviva, D.E. and Bourret, P. (1949) Considérations sur l'emploi des plaques de nylon dites Crinoplaques comme materiel de plastie parietale. Congrés Français de Chirurgie 52ème Session, Paris, 453.

[6] Usher, F.C., Cogan, I.E. and Lowry, T.I. (1960) A New Technique for the Repair of Inguinal and Incisional Hernias. Archives of Surgery, 81, 847-854. http://dx.doi.org/10.1001/archsurg.1960.01300050169030

[7] Lichtenstein, I.L. (1970) Hernia Repair without Disability. The C.V. Mosby Company, St. Louis.

[8] Fruchaud, H. (1956) Le Traitement Chirurgical des Hernies de l’Aine chez l’Adulte. G. Doin \& Cie, Paris, $285-294$.

[9] Schumpelick, V. (2005) Hernia Repair. AHS Meeting, San Diego, 9-12 February 2005, Abstract 46-I.

[10] Baker, R.J. and Fischer, J.E. (2001) Mastery of Surgery. 4th Edition, Lippincott Williams \& Wilkins, Philadelphia, 1930, Table 4.

[11] Bay-Nielsen, M., Perkins, F.M. and Kehlet, H. (2001) Pain and Functional Impairment 1 Year after Inguinal Herniorrhaphy: A Nationwide Questionnaire Study. Annals of Surgery, 233, 1-7. http://dx.doi.org/10.1097/00000658-200101000-00001

[12] Page, B., Paterson, D., Young, D., et al. (2002) Pain from Primary Inguinal Hernia and the Effect of Repair on Pain. British Journal of Surgery, 89, 1315-1318. http://dx.doi.org/10.1046/j.1365-2168.2002.02186.X

[13] Nienhuijs, S.W., Boelens, O.B.A. and Strobbe, L.J.A. (2005) Pain after Anterior Mesh Hernia Repair. Journal of the American College of Surgeons, 200, 885-889. http://dx.doi.org/10.1016/j.jamcollsurg.2005.02.005

[14] Aasvang, E. and Kehlet, H. (2005) Chronic Postoperative Pain: The Case of Inguinal Herniorrhaphy. British Journal of Anaesthesia, 95, 69-76. http://dx.doi.org/10.1093/bja/aei019

[15] Kehlet, H., Jensen, T.S. and Woolf, C.J. (2006) Persistent Postsurgical Pain: Risk Factors and Prevention. Lancet, 367, 1618-1625. http://dx.doi.org/10.1016/S0140-6736(06)68700-X

[16] Fränneby, U., Sandblom, G., Nordin, P., et al. (2006) Risk Factors for Long-Term Pain after Hernia Surgery. Annals of Surgery, 2, 212-219. http://dx.doi.org/10.1097/01.sla.0000218081.53940.01

[17] Poobalan, A.S., Bruce, J., Smith, W.C., et al. (2002) A Review of Chronic Pain after Inguinal Herniorrhaphy. The Clinical Journal of Pain, 191, 48-54.

[18] Ferzli, G.S., Edwards, E., Al-Khoury, G. and Hardin, R. (2008) Postherniorrhaphy Groin Pain and How to Avoid It. Surgical Clinics of North America, 88, 203-216. http://dx.doi.org/10.1016/j.suc.2007.10.006

[19] Bloomberg News (2013) Johnson \& Johnson Discloses Government Probe of Hip Implants, Surgical Mesh. http://www.nj.com/business/index.ssf/2013/02/johnson_johnson_discloses_gove.html

[20] Rosenberg, B. National Meshoma Foundation Fort Lauderdale FL, USA.

[21] Iakovlev, V., Pintilie, M., Morrison, A., et al. (2007) Effects of Distributional Heterogeneity on the Analysis of Tumor Hypoxia Based on Carbonic Anhydrase IX. Lab Investigation, 87, 1206-1217. http://dx.doi.org/10.1038/labinvest.3700680

[22] Iakovlev, V., Gabril, M. and Dubinski, W. (2012) Microvascular Density as an Independent Predictor of Clinical Outcome in Renal Cell Carcinoma: An Automated Image Analysis Study. Lab Investigation, 921, 46-56. http://dx.doi.org/10.1038/labinvest.2011.153

[23] Iakovlev, V., Siegel, E., Tsao, M.S., et al. (2012) Expression of Kallikrein-Related Peptidase 7 Predicts Poor Prognosis in Patients with Unresectable Pancreatic Ductal Adenocarcinoma. Cancer Epidemiology, Biomarkers Prevention, 21, 1135-1142. http://dx.doi.org/10.1158/1055-9965.EPI-11-1079

[24] Henderson, J., Terenghi, G., McGrouther, D.A., et al. (2006) The Reinnervation Pattern of Wounds and Scar May Explain Their Sensory Symptoms. Journal of Plastic, Reconstructive Aesthetic Surgery, 59, 942-950. http://dx.doi.org/10.1016/j.bjps.2005.11.038

[25] Hamed, K., Giles, N., Anderson, J., et al. (2011) Changes in Cutaneous Innervation in Patients with Chronic Pain after Burns. Burns, 37, 631-637. http://dx.doi.org/10.1016/j.burns.2010.11.010

[26] Fornasari, D. (2012) Pain Mechanisms in Patients with Chronic Pain. Clinical Drug Investigation, 32, 45-52. http://dx.doi.org/10.2165/11630070-000000000-00000

[27] Kidd, B.L. and Urban, L.A. (2001) Mechanisms of Inflammatory Pain. British Journal of Anaesthesia, 87, 3-11. http://dx.doi.org/10.1093/bja/87.1.3

[28] Bassini, E. (1889) Nuovo metodo operativo per la cura dell'ernia inguinale. Prosperini, Padova.

[29] Bogros, A.J. (1823) Essais sur l’Anatomie Chirurgicale de la région iliaque et description d'un nouveau procédé pour faire la ligature des artères épigastrique et iliaque externe. Thèse Médicale, Paris. No 153, Edit Didot le Jeune, Paris.

[30] Fruchaud, H. (1956) L’Anatomie Chirurgicale des Hernies de l’Aine. G. Doin Editeurs, Paris. 
[31] Fruchaud, H. (1956) Le traitement Chirurgical des Hernies de l’Aine chez l’Adulte. G. Doin \& Cie, Paris.

[32] Usher, F.C., Fries, J.G., Ochsner, J.L. and Tuttle, L.L.D. (1959) Marlex Mesh, a New Plastic Mesh for Replacing Tissue Defects, Clinical Studies. JAMA Surgery, 78, 138-145. http://dx.doi.org/10.1001/archsurg.1959.04320010140023

[33] Lichtenstein, I.L. (1986) Hernia Repair without Disability. 2nd Edition, Preface to the 2nd Edition, Ishiyaku Euroamerica Inc., St Louis, Tokyo, Page X,

[34] Simmons, M.P., Aufenacker, M., Bay-Nielsen, M., Bouillot, J.L., Campanelli, G., Conze, J., et al. (2009) European Hernia Society Guidelines on the Treatment of Inguinal Hernias in Adult Patients. Hernia, 13, 343-403. http://dx.doi.org/10.1007/s10029-009-0529-7

[35] Fischer, J. (2013) Hernia Repair: Why Do We Continue to Perform Mesh Repairs in the Face of Human Toll of Inguinodynia. American Journal of Surgery, 206, 619-623. http://dx.doi.org/10.1016/j.amjsurg.2013.03.010

[36] Magee, R.K. (1942) “Genitofemoral Causalgia”: A New Syndrome. Canadian Medical Association Journal, 46, 326329.

[37] Lyon, E.K. (1945) Genitofemoal Causalgia Surgically Correctable. Canadian Medical Association Journal, 53, 213.

[38] Bendavid, R. (1992) Dysejaculation: An Unusual Complication of Inguinal Herniorrhaphy. Postgraduate General Surgery, 4, 139-141.

[39] Chevrel, J.P. (1992) The Treatment of Neuralgias Following Inguinal Herniorrhaphy: A Report of 47 Cases. Postgraduate General Surgery, 4, 2.

[40] Canadian Pain Coalition (2006) Media Room.

[41] Coda, A., Bendavid, R., Botto-Mica, F., Bossotti, M. and Bona, A. (2003) Structural Alterations of Prosthetic Meshes in Humans. Hernia, 7, 29-34.

[42] Agrawal, A. and Avill, R. (2005) Mesh Migration Following Repair of Inguinal Hernias: A Case Report and Review of the Literature. Hernia, 9, 96-99. 
Scientific Research Publishing (SCIRP) is one of the largest Open Access journal publishers. It is currently publishing more than 200 open access, online, peer-reviewed journals covering a wide range of academic disciplines. SCIRP serves the worldwide academic communities and contributes to the progress and application of science with its publication.

Other selected journals from SCIRP are listed as below. Submit your manuscript to us via either submit@scirp.org or Online Submission Portal.
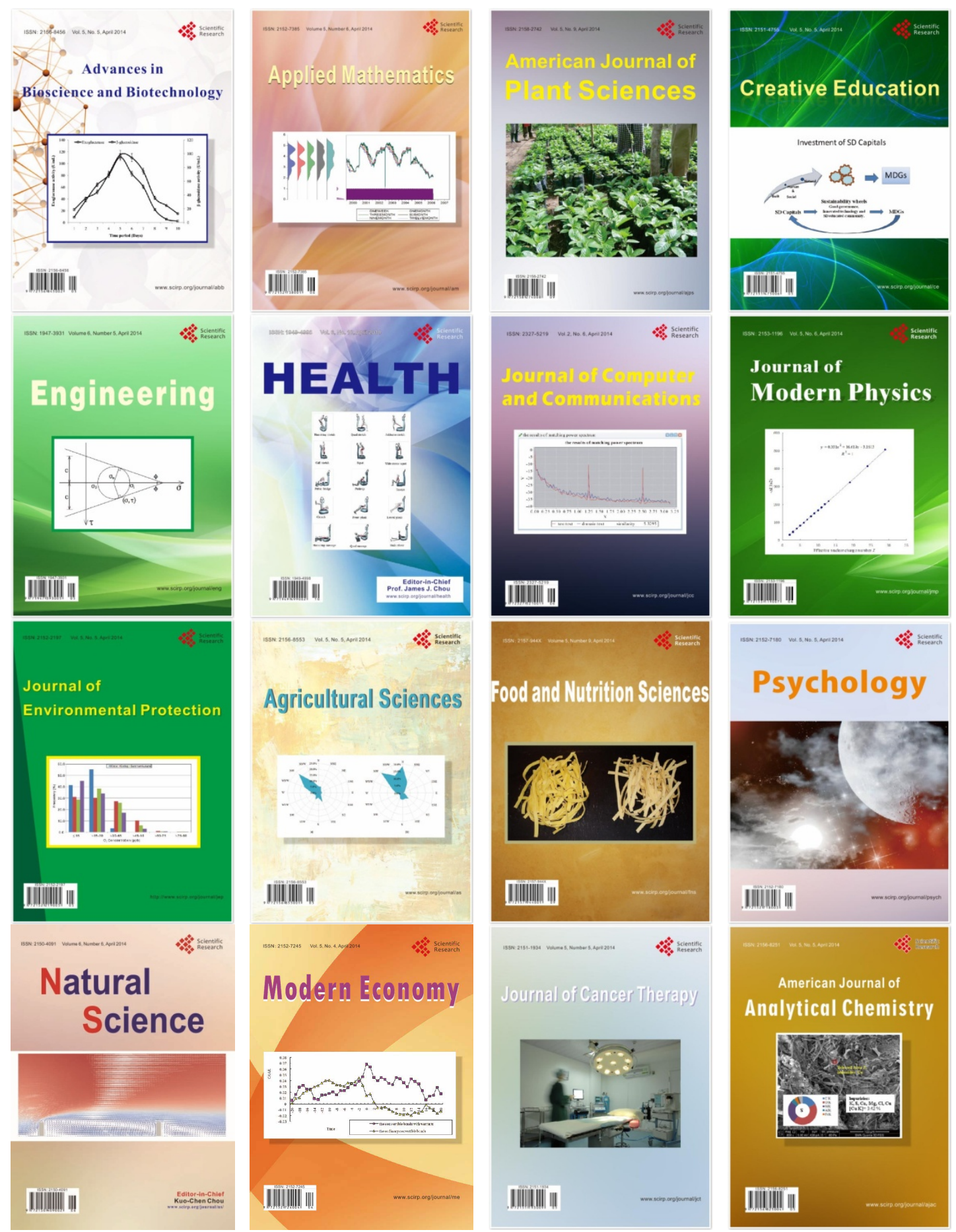